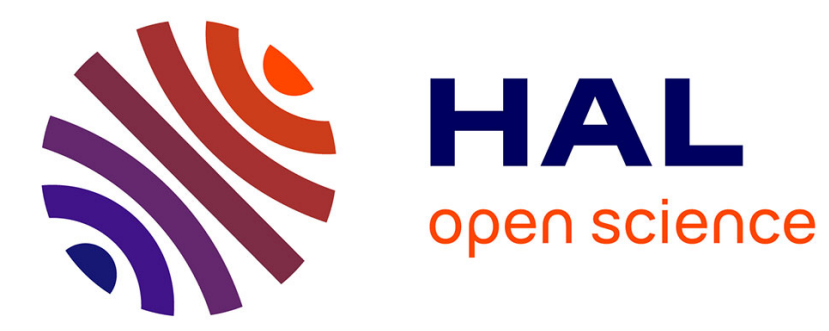

\title{
Impact of Human Activities on Fasciolosis Transmission
}

Emeline Sabourin, Pilar Alda, Antonio Vázquez, Sylvie Hurtrez-Boussès, Marion Vittecoq

\section{To cite this version:}

Emeline Sabourin, Pilar Alda, Antonio Vázquez, Sylvie Hurtrez-Boussès, Marion Vittecoq. Impact of Human Activities on Fasciolosis Transmission. Trends in Parasitology, 2018, 34 (10), pp.891-903. 10.1016/j.pt.2018.08.004 . hal-01904691

\section{HAL Id: hal-01904691 \\ https://hal.umontpellier.fr/hal-01904691}

Submitted on 11 Dec 2018

HAL is a multi-disciplinary open access archive for the deposit and dissemination of scientific research documents, whether they are published or not. The documents may come from teaching and research institutions in France or abroad, or from public or private research centers.
L'archive ouverte pluridisciplinaire HAL, est destinée au dépôt et à la diffusion de documents scientifiques de niveau recherche, publiés ou non, émanant des établissements d'enseignement et de recherche français ou étrangers, des laboratoires publics ou privés. 


\title{
Impact of Human Activities on Fasciolosis Transmission
}

\author{
Emeline Sabourin, $, 2, *$ Pilar Alda, ${ }^{2,3}$ Antonio Vázquez, ${ }^{4}$ Sylvie Hurtrez-Boussès,,${ }^{2,5}$ and Marion Vittecoq ${ }^{1,2}$ \\ 1 Institut de recherche de la Tour du Valat, Arles, France \\ 2MIVEGEC, University of Montpellier, CNRS, IRD, Montpellier, France 3Universidad Nacional del Sur, Bahía Blanca, Argentina \\ 4Instituto de Medicina Tropical Pedro Kourí, Ciudad de La Habana, Cuba 5Département de Biologie-Ecologie, Faculté des Sciences, University of \\ Montpellier, Montpellier, France
}

How to cite :

Sabourin E., Alda P., Vázquez A., Hurtrez-Boussès S., Vittecoq M. 2018. Impact of Human Activities on Fasciolosis Transmission. Trends in Parasitology [Internet] [cited 2018 Sep 25]; https://doi.org/10.1016/j.pt.2018.08.004. doi: 10.1016/j.pt.2018.08.004

Fasciolosis is a worldwide disease caused by the liver fluke Fasciola spp. This food-and water-borne disease is a major public health and veterinary issue. It is currently (re)emerging in several regions mostly due to the rapid evolution of human activities. This article reviews the current knowledge of the impact of irrigation-system management, livestock management, and human diet and hygiene habits on the emergence of fasciolosis. We also identify the gaps in this knowledge and the possible solutions for limiting these impacts. Integrated control seems to be the most effective solution for controlling fasciolosis, because it enables monitoring, prevention, and rapid action in case of the (re)emergence of the disease.

\section{A Neglected Disease with a Significant Burden}

Infectious diseases have emerged and re-emerged over the last hundred years, resulting in a complex public health crisis. These (re)emergences are largely due to anthropic disturbances, which modify pathogen dynamics by creating new contacts between hosts, favouring parasite dispersal and intensifying selection pressure on parasites [1,2]. Water-borne diseases (e.g., bilharzia, cholera, and fasciolosis) are particularly sensitive to human disturbance. Indeed, massive urbanization, expansion of irrigated areas, and transformation of natural wetlands in agricultural lands are all likely to promote the (re)emergence of water-borne diseases, which have major impacts on human health. For instance, the use of inadequately treated wastewater in irrigation and faecal sludge in soil amendment or fertilization are often associated with an elevated prevalence of intestinal helminth infections and diarrhoeal diseases in both workers and food consumers [3]. In order to reduce the impact of human activities on health, we need to better understand the mechanisms that drive water-borne diseases.

Water-borne diseases transmitted by trematodes are found throughout the world and have a strong impact on the economy and health $[1,4]$. Trematodes have complex life cycles involving vertebrates as definitive hosts and usually, almost as a rule, snails as the first intermediate host [5]. Trematodes infect more than one billion

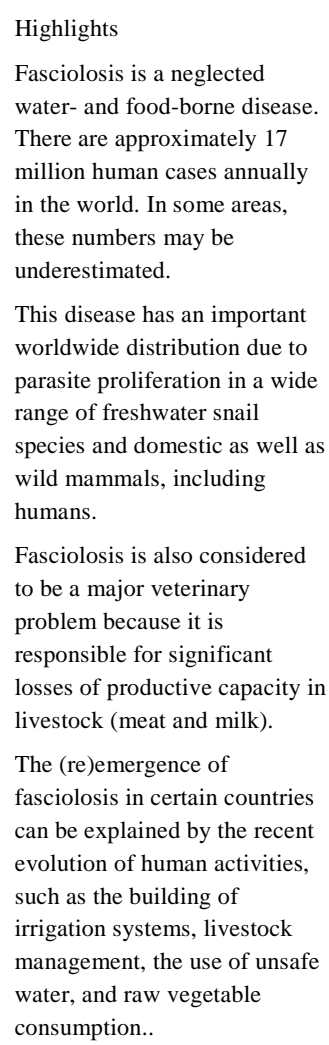

This disease has an important worldwide distribution due to parasite proliferation in a wide range of freshwater snail species and domestic as well as wild mammals, including humans.

Fasciolosis is also considered to be a major veterinary problem because it is responsible for significant losses of productive capacity in livestock (meat and milk).

The (re)emergence of fasciolosis in certain countries can be explained by the recent evolution of human activities, such as the building of irrigation systems, livestock management, the use of unsafe water, and raw vegetable consumption. people and cause more than 600 million disabilityadjusted life years (DALYs) (see Glossary) annually [6,7]. Many human activities increase the risk of becoming infected by trematodes. For instance, the development and management of water resources increase the prevalence of schistosomiasis and fasciolosis in several tropical areas $[3,8,9]$.

Fasciolosis is a water- and food-borne disease caused by two trematodes: the liver flukes Fasciola hepatica and Fasciola gigantica. F. hepatica has a worldwide distribution, while F. gigantica transmission is limited to certain areas in Africa and Asia [10-17]. These two species also coexist in some areas where mixed infections and hybridization have been reported [18-20]. More literature exist about F. hepatica transmission since it is considered as the distinction of the two species can be difficult depending on the diagnosis methods [21,22]. Thus, the prevalence of F. gigantica might be underestimated, and the development of a fast molecular diagnosis to differentiate the two species will be essential for effective control and prevention. The life cycle of Fasciola spp. involves a very wide range of domestic and wild mammals (sheep, cattle, horse, camel, coypu, rabbit etc.) including humans as the definitive host [3] (Figure 1). The intermediate host is a snail that inhabits bodies of freshwater. Major sources of infection for definitive hosts are plants associated with water or spring water [23]. Indeed, the metacercariae (i.e., infective stages) can encyst on the surface of water and aquatic plants [24]. Fasciolosis affects mainly people living in poverty, mostly children, without adequate sanitation and in close contact with livestock. It is considered as a highly neglected tropical disease $\mathrm{i}^{\mathrm{i}}$. At present, estimates for all continents reach 17 million people infected [25]. However, the number is probably underestimated in many countries, particularly in Asia and Africa [26]. The real number of cases could be between 35 and 72 million people, with more than 180 million people at risk of infection [27]. Fasciolosis is re-emerging in certain areas. For example, in Vietnam, 500 human cases were reported in 12 provinces in 2000, while over 20000 cases were observed in 52 provinces in $2012^{\mathrm{ii}}$. Diagnosing fasciolosis is not particularly easy in numerous countries where many diseases affect human populations. Moreover, in some rural areas, most infected inhabitants cannot go to medical centres for diagnosis, and misdiagnosis may sometimes occur due to insufficiently suggestive symptomatology [28,29] (Box 1). Both aspects have already been noted in several human fasciolosis-endemic areas in Bolivia, Peru, Mexico, and Egypt. As is true of other neglected diseases, fasciolosis infections are usually nonfatal, clinically mild, and not reported, but they are disabling diseases that maintain or increase poverty with 197000 DALYs estimated [30]. 
Fasciolosis is also considered to be a major veterinary problem since it is responsible for important losses in the productive capacity of livestock (meat and milk) [31]. For instance, in the Irish and UK farming industry, fasciolosis is responsible for the annual loss of over $£ 80$ million [32]. The liver flukes cause serious digestive illness, anaemia, and sometimes cirrhosis, which can be lethal in livestock [33]. Treatmen $t$ is long and expensive, and cases of parasite resistance have been described [34]. Liver flukes have a great ability to proliferate in a wide range of different freshwater ecosystems. Indeed, fasciolosis is recognized to have a worldwide latitudinal and longitudinal distribution [30]. This wide distribution makes it possible to study its parasite dynamics in different habitats with diverse definitive and intermediate hosts. Yet, it greatly complicates disease control, because solutions must be adapted to very different environmental and socioeconomic contexts.

The purpose of this review is to assess the existing knowledge on the effects of human activities and habits on the risk of fasciolosis. We focus on three groups of human activities that are mentioned in the literature as the main factors affecting fasciolosis: (i) irrigation-system management, (ii) livestock management, and (iii) human diet and hygienic habits. For each of these activities, we gathered available data to highlight knowledge gaps and perspectives and to identify solutions that may help mitigate the risk of fasciolosis transmission through preventive measures and control strategies.

\section{Irrigation-System Management}

Similar to other vector-borne diseases, such as malaria or schistosomiasis, the vectors of fasciolosis tend to proliferate in man-made irrigation systems, leading to severe consequences on human and animal health $[11,26,35]$. Liver flukes, unlike most trematodes, infect a wide range of intermediate hosts living in a wide range of freshwater habitats (irrigation canals, ditches, rivers, dams, and lakes) [36,37]. These intermediate hosts belong to several species of freshwater snails, mainly within the family Lymnaeidae [38], but also within the family Planorbidae [39] and the terrestrial group Succineidae [40]. Most of the snail species recognized to be major vectors of fasciolosis reproduce by self-fertilization, which leads to a great capacity to quickly colonize new habitats or recolonize after extinction events [41-43]. For example, the vector of fasciolosis, Pseudosuccinea columella, which is probably native to North America, colonized South America,

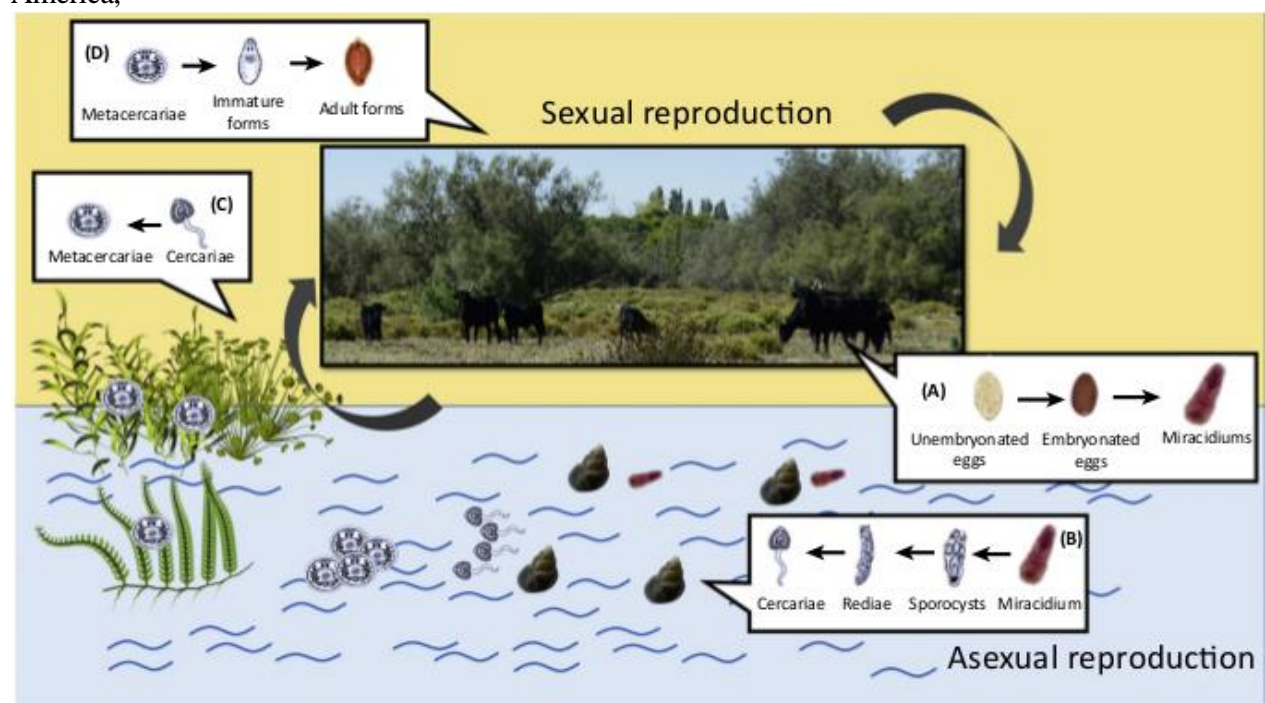

\section{Glossary}

Disability-adjusted life years (DALYs): one DALY can be thought of as one lost year of 'healthy' life. The sum of these DALYs across the population, or the burden of disease, can be thought of as a measurement of the gap between the curren health status and an ideal health situation, in which the entire population lives to an advanced age, free of disease and disability. Integrated parasite control: a system of control which considers the preservation of the ecosystem and human health. It integrates all control methods (chemical, biological, physical etc.)

limiting the utilization of chemical products except if no other method is available. Neglected diseases: these diseases include a diverse group of communicable diseases that affect humans in tropical and subtropical countries. They involve more than one billion people and cost developing economies billions of dollars every year. Populations living in poverty, without adequate sanitation, and in close contact with infectious vectors, domestic animals, and wildlife are those worst affected. Preventive chemotherapy: this is defined as the administration of a single safe medicine, either alone or in combination with other medicines, as a public health intervention to prevent selected neglected tropical diseases.

Self-fertilization: fertilization of female gametes by male gametes from the same individual, as by sperm from the same animal in hermaphroditic species or by pollen from the same plant.

Figure 1Fasciola spp. Transmission Cycle. (A) First unembryonated eggs are released via the faeces of the definitive host. Once in the water, the eggs become embryonated and release miracidium larvae that will swim to the intermediate host, a freshwater snail. (C) The cercariae encyst, preferably on the vegetation or on the surface of the water. The encysted stages are metacercariae. (D) These metacercariae will be ingested by the definitive host, through drinking water or eating aquatic plants. Once in the mammal, the metacercariae migrate into the bile ducts to reach their adult form. Sexual reproduction then takes place and produce eggs that come out through the digestive tract and faeces.

Africa, Europe, and the Pacific islands in less than a century [42]. Another vector, Galba truncatula, invaded the Bolivian Altiplano during the 20th century, inducing the highest hyperendemic level of fasciolosis recorded so far [44]. Human activities linked to freshwater ecosystems are a relevant dispersal factor notably due to natural and artificial connections between rivers and irrigation canals facilitating the installation of freshwater invaders $[45,46]$. This high invasiveness has probably facilitated the worldwide expansion of fasciolosis.

For instance, in Senegal, hydroagricultural improvements and dam construction have led to significant environmental modifications (creation of reservoirs and irrigation canals), which in turn have created favourable conditions for the proliferation of the snail species Radix natalensis and Biomphalaria pfeifferi, the intermediate hosts of F. gigantica and Schistosoma mansoni, respectively [47]. In the Peruvian Altiplano, the construction of irrigation and drainage canals caused the proliferation of lymnaeid snails and consequently a higher prevalence of fasciolosis [48]. Unlike irrigation canals that permanently conduct water, drainage canals can become dry so there is no typical aquatic vegetation. However, lymnaeids can live in both habitats because they can survive severe droughts [43]. Indeed, lymnaeid species are amphibious; G. truncatula and Galba cubensis can live in dry habitats by burrowing partially or completely into the soil $[49,50]$. In Spain, the government of the autonomous 
community of Castilla y León has funded the installation of modern irrigation systems to encourage new crops since 1990. Man-made modifications of the environment have contributed to the creation of new habitats for the intermediate hosts and have favoured the emergence of fasciolosis [51]. These studies show that such constructions induce a higher sanitary risk. However, irrigation-system management can be combined with other parameters, which can increase the exposure period of infection. For example, in Pakistan, the first annual peak of fasciolosis is associated with artificial irrigation but the second peak is driven by rainfall [52]. Despite some insights into how irrigation-system management promotes snail proliferation and consequently increases the prevalence of fasciolosis, very few studies have been carried out both before and after the installation of irrigation. Preliminary epidemiological studies before the construction are needed to evaluate the epidemiological risks of any man-made irrigation.

\section{Which Solutions Can Limit Intermediate Host Proliferation in Irrigation Systems?}

Dams and irrigation canals are used to develop agriculture and the economy. Therefore, we need to assess the trade-off between the benefits and the cost of irrigation systems. One of the solutions proposed to prevent fasciolosis in regions with dams and irrigation canals is to prevent the proliferation of the intermediate host.

One solution is the use of molluscicides, which was highly recommended during the 1970s but has been abandoned because most products are toxic for the macrofauna that inhabit the freshwater environment [31,53]. Only a few studies have been conducted to test natural molluscicides [54,55]. A recent study on a new biomolluscicide, Citrullus colocynthis, shows that it kills the snail vector of fasciolosis, G. truncatula and also the larvae of F. hepatica without affecting the associated fauna of the snail [56].

Another solution proposed is the use of biological control. Population dynamics studies are important for biological control strategies because they allow us to know the high mortality and reproduction seasons of freshwater snails; this information is needed for the effective introduction of biological agents (predators, competitors) [57,58]. Rondelaud et al. [59] used the predator mollusc Zonitoides nitidus to eliminate lymnaeid snails G. truncatula and Omphiscola glabra. This practice was not effective, probably because of the complexity of applying this method in the wild by nonspecialists, and the variations in snail population dynamics as a function of the environmental conditions (temperature and rainfall).

The last method is physical control, which involves cleaning canals by removing aquatic vegetation. This cleaning can be very effective because it can be durable and selective against specific snail species. The most relevant requirement is to target all the habitats covered by macrophytes and algae where the snails live because a single snail propagule can rapidly recolonize the whole irrigation system. This technique can be applied if canals are regularly cleaned and if they are not damaged. Poor maintenance of canals can lead to rapid recolonization by snails [60]. Indeed, if the canals are not cleaned properly, plants containing parasite eggs will be left on site and snails can remain in sediment, allowing them to rapidly recolonize the habitat. Moreover, by dispersing eggs, some birds and aquatic mammals can favour the spread of freshwater snails, leading to the recolonization of certain areas $[61,62]$.

Any single control strategy cannot effectively reduce fasciolosis transmission. Integrated parasite control programs are needed to limit fasciolosis. In Peru, dairy cattle producers decreased the prevalence of F. hepatica in cattle from $63 \%$ to $14 \%$ in 2 years by applying an integrated parasite control program [63]. They achieved this control not only through the improved drainage of ditches, but also through training sessions on fasciolosis, including manuals with calendars stating the correct use and administration of antiparasitic treatment, technical assistance with follow up visits, and strategically timed treatments. Irrigation canals were cleaned and the slope of the canal banks was increased to approximately $130^{1}$. These steps allowed sun rays to fall on the bottom and sides of the ditches for the longest possible duration, reducing the shaded areas where the snails Galba viator (called Fossaria viatrix in the article) were located.

\section{Livestock Management}

Every integrated parasite control program must also take account of the management of the definitive host. The occurrence of fasciolosis in herds is positively correlated with the presence of snail habitats including streams, irrigation canals, and dams [64]. Indeed, herds become infected when eating aquatic plants or drinking water contaminated with Fasciola metacercariae. Grazing and water access are thus key factors in the spread of fasciolosis. It has been shown that the risk of fasciolosis increases in regions with long grazing seasons [65]. In temperate zones, seasonal transmission can be observed when the temperature is appropriate and water is available for snail reproduction, hence, for parasite development [31]. In tropical zones, herds are more easily in contact with liver flukes during the rainy season [52]. During the dry season, herd management permits contact between herds and parasites. For instance, in Tanzania, infection rates of F. gigantica and paramphistomes were higher in villages where herds grazed freely in irrigated crops [14].

All of these factors play a role in the small scale of one farm, but the trade of animals between farms may also contribute to spreading fasciolosis [66,67]. Moreover, the expansion of fasciolosis around the world has been shaped by the continuous export of livestock [30]. For instance, ITS-1 and ITS-2 sequences do not differ between Bolivian and Spanish strains of F. hepatica, and they exhibit only a few differences with liver-fluke samples in other parts of the world [68], suggesting recent exchanges between populations, most probably due to livestock trade [69]. Common mitochondrial restriction fragment length polymorphism (RFLP) haplotypes have been consistently found in the Republic of Ireland, Greece, and Australia [70]. In many European and African countries, a seasonalmovementofpeople withtheirherds occursbetweenseasons. Forinstance, when animals move from Iranian lowlands (usually contaminated with F. gigantica) to the neighbouring highlands (usually contaminated with F. hepatica), animals become coinfected with both parasite species [71]. The risk of fasciolosis can be limited through the management of those habitats and/or through the adaptation of livestock management. Many methods are available for limiting the transmission of fasciolosis to livestock. 
How Can Livestock Management Be Adapted to Controlling Fasciolosis Risk?

First, animals, pastures, and periods of high risk should be identified at each farm. Second, a combination of measures adapted to each farm should be taken. Since each farm might experience different conditions, it s essential to identify the risk on each farm, and to set up the appropriate integrated solution. Finally, fasciolosis prevalence and the emergence of anthelmintic resistance should be regularly monitored to assess the effectiveness of the measures and to readapt them if necessary. Measures of control include the regulation of grazing, anthelmintic treatments, and consideration of tolerance or genetic resistance to the parasite. First, farmers can limit the access of herds to snail habitats. It is possible to isolate herds from water sources at risk by fencing [72], and also by adding water tanks that are regularly cleaned to avoid snail invasion. However, this method is not always effective because, during the rainy season, snails can move to fenced habitats and then develop in ditches made by cattle trampling [53]. For example, snail migrations over $30 \mathrm{~m}$ have been observed from one spring swamp, in the middle of a pasture grazed by dairy cows, to puddles at the edge of the pasture [72]. Recent studies have explored the use of very high-resolution satellite and drone imagery to map small water bodies and populations of intermediate host snails in pastures, but further research is required to make this approach operational, and to give advice that is adapted to the situation of a specific local farm [73,74].

Second, the risk of infection can also be reduced by moving animals to uncontaminated pastures and avoiding grazing with fodder supplementation [75]. However, resources are sometimes scarce and there are not always enough pastures available to feed animals. Thus, other methods such as anthelmintic treatments can be used. In sub-Saharan Africa, nomadic pastoralists use the banks of Lake Chad as herd pastures. A study shows that animals that have grazed near the lake for long periods have a high risk of infection [76]. Limiting the access to the lake is impossible since no alternative source of water or grazing resources exist nearby, which means that the alternative solution is to treat cattle with triclabendazole (TCBZ), or other drugs against liver flukes. Yet, there is an increasing resistance of liver flukes to anthelmintics, in particular to TCBZ, which is the most widely used drug [77]. Before 2011, TCBZ resistance has been reported in sheep and cattle in six farms in Australia, Scotland, Wales, The Netherlands, Spain, and the Republic of Ireland. Since then, 24 other farms have also reported resistance to this anthelmintic in Northern Ireland, Scotland, Wales, Australia, New Zealand, Peru, and Argentina [34].

Alternative chemical options are available to target TCBZ-resistant flukes, including treatment with clorsulon, nitroxynil, closantel, albendazole, or oxyclozanide, according to the host species [34,77]. Nevertheless, it is important to use alternative chemicals more strategically than how TCBZ has been used historically to avoid the emergence of new resistances. For example, the annual rotation of drugs usually prevents the development of resistance, particularly if the drugs are from different classes and act differently [78]. Farmers can also select the animals to be treated. They can treat the most vulnerable animals (for instance, the youngest) to reduce the number of individuals treated and thus the selection pressure leading to resistance. It is also important to set up surveillance systems that monitor infection status at farm level on a regular basis (Box 1). For instance, one study shows that such longitudinal monitoring approaches can be an effective decision support tool for reducing infections on Irish farms [79]. However, the increasing resistance to the limited number of available flukicides makes finding an alternative control method crucial. Vaccines have been considered as a promising and economically viable alternative strategy for the control of fasciolosis in livestock [80,81], but more research is needed before they can be used [77].

Anthelmintic treatments can be coupled with pasture rotation [82]. This method is feasible if the habitats of intermediate hosts are well identified and some safe and uncontaminated pastures are available. Cattle can graze in safe pastures during spring and autumn when the risk ofgetting infected is low, and can then be treated before moving to contaminated pastures during summer. However, the risk of promoting resistance to anthelmintics is high, because flukes would be in contact with recently treated cows. Thus, if eggs are eventually shed they will all come from resistant strains [72]. There are also some alternative methods to chemical treatments, such as deworming plants (Agrimonia eupatoria, Urtica dioica, Calendula officinali), but they must be combined with good livestock management, including the rotation of herds between pastures and safe and uncontaminated food and wateriii.

Every integrated parasite control program is a three-step process. First, animals, pastures, and periods of high risk should be identified at each farm. Second, a combination of measures adapted to each farm should be taken. Since each farm might experience different conditions, it

is essential to identify the risk on each farm, and to set up the appropriate integrated solution. Finally, fasciolosis prevalence and the emergence of anthelmintic resistance should be regularly monitored to assess the effectiveness of the measures and to readapt them if necessary.

Measures of control include the regulation of grazing, anthelmintic treatments, and consideration of tolerance or genetic resistance to the parasite. First, farmers can limit the access of herds to snail habitats. It is possible to isolate herds from water sources at risk by fencing [72], and also by adding water tanks that are regularly cleaned to avoid snail invasion. However, this method is not always effective because, during the rainy season, snails can move to fenced habitats and then develop in ditches made by ca

Finally, another tool for fasciolosis control is to manage herd genetic resources to enhance the resistance or tolerance to fasciolosis in livestock populations. It has been shown that native populations may be resistant to certain diseases. For example, Red Massai sheep are resistant and resilient to gastrointestinal nematodes [83], and some sheep breeds are resistant to F. gigantica - such as the Indonesian thin-tailed sheep. In contrast, this breed is susceptible to F. hepatica $[84,85]$. This resistance and resilience can be explained by hundreds of years of coevolution between the parasites and the hosts, but this tool must be part of an integrated management program. Moreover, in rural zones, herds are regularly in contact with humans, promoting the emergence of fasciolosis in human populations. 
The transmission of fasciolosis to humans is linked to water and food. Drinking unsafe water, eating raw or undercooked contaminated vegetables, and applying inappropriate agricultural practices are the main reasons for the (re)emergence or persistence of fasciolosis in human populations worldwide [3]. In some countries (Vietnam, Bolivia, Iran, Egypt, Ethiopia), high incidence of human fasciolosis is explained by the extensive breeding of livestock in close contact with humans combined with the traditional consumption of watercress, an aquatic plant in which larvae of Fasciola spp. usually become encysted $[18,86]$. Vietnamese rural populations have a higher prevalence of fasciolosis than urban populations because people drink water and eat aquatic plants from water bodies that are in close contact with livestock [18]. In Argentina, several outbreaks of fasciolosis were caused by the ingestion of watercress naturally growing along river and stream beds that is collected during recreational activities [28].

Inappropriate agricultural practices can also promote the emergence and persistence of fasciolosis. For instance, farmers in Ethiopia irrigate vegetables during the dry season, promoting a good environment for snail proliferation; it results in the appearance of endemic fasciolosis [19] (Figure 2). In Ghana and Egypt, unsafe water is used for plant irrigation, leading to the contamination of plants by F. hepatica [87]. People can also become infected with Fasciola spp. if they have no access to safe water inside their homes and use water from irrigation and drainage canals for their needs: drinking, cooking, personal hygiene, cleaning, and washing $[9,19]$.

In most countries, not only habits but also socioeconomic factors can explain the (re)emergence and persistence of fasciolosis. Sometimes, the risk of infection may vary widely among different groups of people and villages, based on cultural, environmental, and socio-economic differences. In Bolivia, people become infected mostly by eating uncooked contaminated aquatic plants. Bolivian children eat watercress and other aquatic plants when they help their parents in farming activities, while in Peru children become infected mostly by drinking contaminated water while playing in drainage canals $[9,88,89]$. This illustrates why aquatic plant consumption, irrigation of crops with contaminated water, and the use of irrigation canals for human needs.
Outstanding Questions

What are the wild reservoirs of fasciolosis? How do they contribute to endemicity, emergence or re-emergence?

How can the impact of wildlife on fasciolosis be assessed?

How do global changes impact fasciolosis transmission, and how do they affect the risks of (re)emergence?

What is the distribution of vectors at the global and local scale? How is it impacted by human activities?

What are the compatibilities between liver flukes and definitive hosts (wild versus domestic)?

How can we effectively combine awareness-raising, prevention, and monitoring to limit fasciolosis emergence in human populations? What are the interactions of fasciolosis with other diseases in humans, livestock, and wild animals?

How do we evaluate which socioeconomic and ecological contexts can increase the risk of the emergence of fasciolosis?

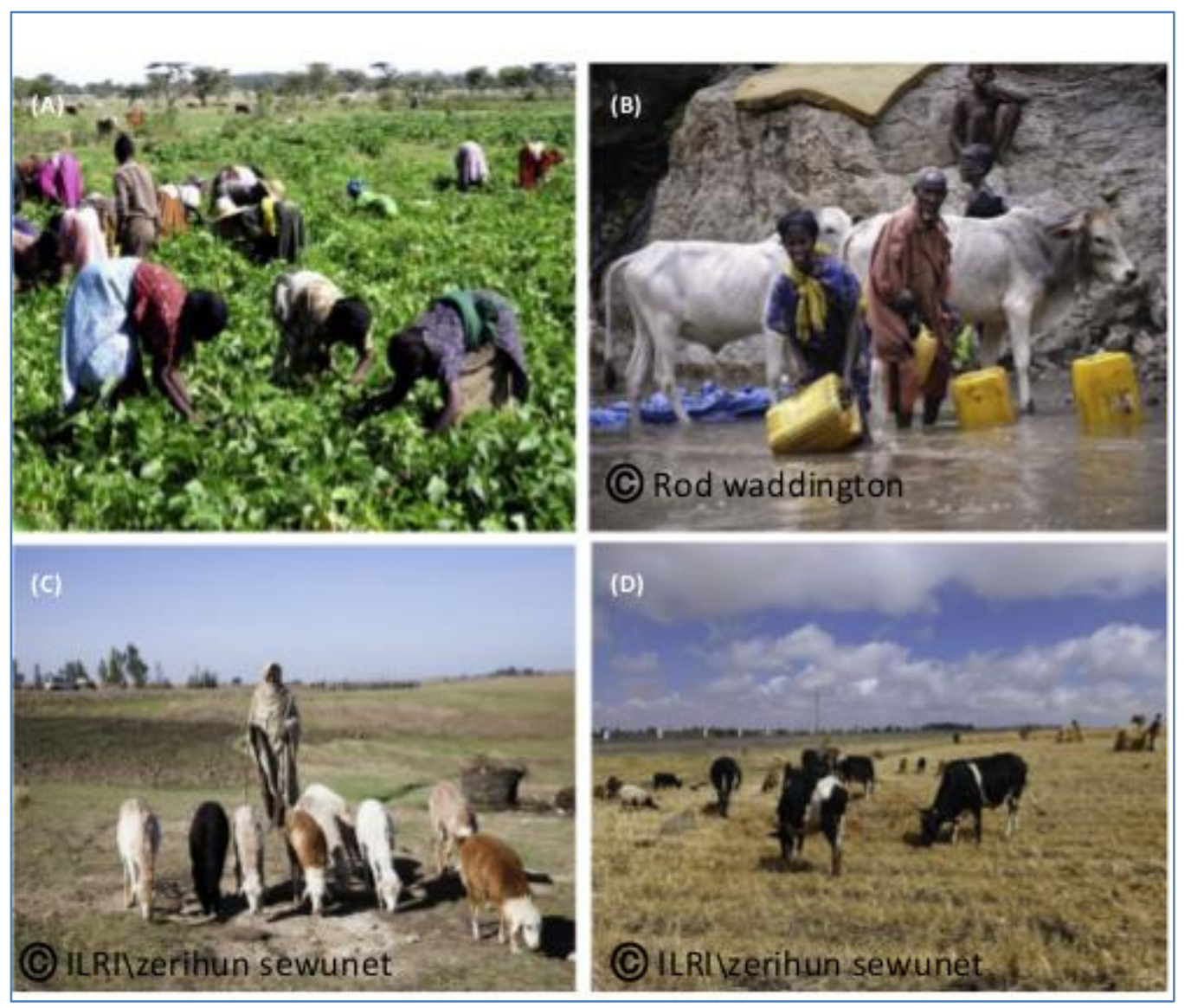

Figure 2 . A Case Study, the Work of Fentie et al. in Ethiopia [19]. Growing vegetables is crucial in the region (A). Irrigation canals are built to irrigate fields, but these canals can also favour fasciolosis transmission because they can be contaminated by animal faeces and are good habitats for freshwater snails. Fields can be contaminated during irrigation, infesting the people who consume raw vegetables or drink unsafe water due to no access to safe water. (B) Local people breed sheep, cattle, or horses. Animals are close to humans. Ç,D) Domestic animals drink in irrigation canals and rivers, which are also used by humans. Moreover, in this study, the same factors play a role in both fasciolosis and schistosomiasis transmission. This example shows that it is important to consider each risk factor to limit disease emergence. Indeed, the factors described above can be linked to each other. In this case, integrated control can be a good solution for the fight against schistosomiasis and fasciolosis transmission in both humans and livestock 
Which Strategies Can Be Implemented to Prevent Fasciolosis in Humans?

Once the risk factors are identified, several strategies can be used to prevent fasciolosis.

Educational campaigns encouraging people to eat cooked vegetables rather than raw ones can be developed [48]. Indeed, health education is crucial for preventing diseases. For instance, in Central Vietnam, in a community where the prevalence of fasciolosis is high, health volunteers take training courses to improve their skills and knowledge of fasciolosis diagnosis, treatment, surveillance, and management in order to detect and manage cases of fasciolosis (Box 1). At the same time, in the community and at schools, a campaign has been organized to raise public awareness about the parasite's life cycle, transmission, impacts, and control measures (Tran Minh Quy, Doctor of Public Health thesis, University of Wollongong, 2016). Health education was combined with human chemotherapy, vector control, pasture management, and animal treatment, permitting a significant decrease in the prevalence of fasciolosis.

The establishment of a drinking water and sewage-treatment system besides irrigation canals is very important [19,48], and preventive chemotherapy with TCBZ [90] is also possible. This method is used by the WHO as the main way to control most of the trematodes, which has proven effective and safe when the medicine is administered as a single-dose tablet in highlyendemic areas (where individual diagnosis is complicated) [90]. TCBZ reduces the rate of egg production, but it must be coupled with other preventive strategies in order to be $100 \%$ effective. Most of the anthelmintics protect patients for only a short time; thus, this method should be part of a global preventive and treatment approach. Limiting the risk of fasciolosis infection is essential for patients. Monitoring the effectiveness of prevention methods with the implementation of regular diagnoses can reduce disease and help to better target treatments. Indeed, establishing a good diagnosis is essential.

\section{Box 1. Fasciolosis Diagnosis}

\section{Diagnosis in Humans}

There are various diagnostic methods for fasciolosis, depending on different stages and manifestations of the disease:

acute phase or chronic phase [27].

The typical symptoms in the acute phase include fever, nausea, a swollen liver, and extreme abdominal pain.

During the chronic phase, the symptoms are intermittent pain, jaundice, and anemia.

People with symptoms are usually diagnosed by using several of the complementary diagnostic tests described below.

Imaging (ultrasound) and detection in stools by PCR can also be used.

If there is a potential risk of contamination, systematic screening can be used in a population. In this case only one

technique is used, usually based on stool analysis.

Blood Test Diagnosis

During the acute phase, a simple blood test is possible; fasciolosis is suspected if a high number of specific white blood cells (called eosinophils) are found.

Diagnosis by Detecting Eggs in Faeces

The Kato-Katz technique is a quantitative method for detecting parasite eggs in stool samples. It is simple, rapid, and inexpensive, making it an option suitable for field conditions and large-scale studies. It is a specific but not very sensitive diagnostic test that is unable to diagnose the disease during the incubation and acute phases [90].

Diagnosis by ELISA

Immunological tests allow diagnosis of fasciolosis by detecting specific antigens in serum and stool samples, such as FES-Ag (Fasciola excretory-secretory antigens). Serological tests, such as Fas2-ELISA or CL1-ELISA, are able to detect the circulating IgG antibodies. These techniques are highly sensitive and specific [90]. The intermittent clinical signs and symptoms of fascioliasis can be confused with those of other hepatobiliary disorders, causing delayed and difficult diagnosis.

\section{Diagnosis in Animals}

Animal symptoms are anaemia, weight loss, decreased fertility, and mortality in young individuals [31].

The health of the herd can be tested by sampling faeces randomly or by using an immunological test on milk. Individuals can also be tested if they show symptoms.

Diagnosis by Detecting Eggs in Faeces

Coprological sedimentation methods are routinely used for diagnosis of animal infection, and methods such as FLOTAC [93] are available.

Diagnosis by ELISA

Many immunological techniques having high sensitivity, reproducibility, and cost-effectiveness can be used on stools, milk, or serum samples [77]. A few examples of these tests are the SVANOVIR ELIS A, MM3-Sero ELISA, and MM3COPRO ELISA [94-97].

\section{Innovations}

Molecular diagnostic methods are still under development to increase the sensitivity and the specificity of conventional diagnostic tests. One of the new methods is the loop-mediated isothermal amplification (LAMP) assay which would make it possible to detect fluke DNA in stool faster and easier than by PCR, but with an equal level of sensitivity [98]

Various methods exist, but the most common one is stool examination for egg detection, which is still considered to be a conclusive diagnosis despite its low sensitivity [90]. Others methods include testing for eosinophilia, 


\section{Key Figure \\ Integrated Parasite Control}

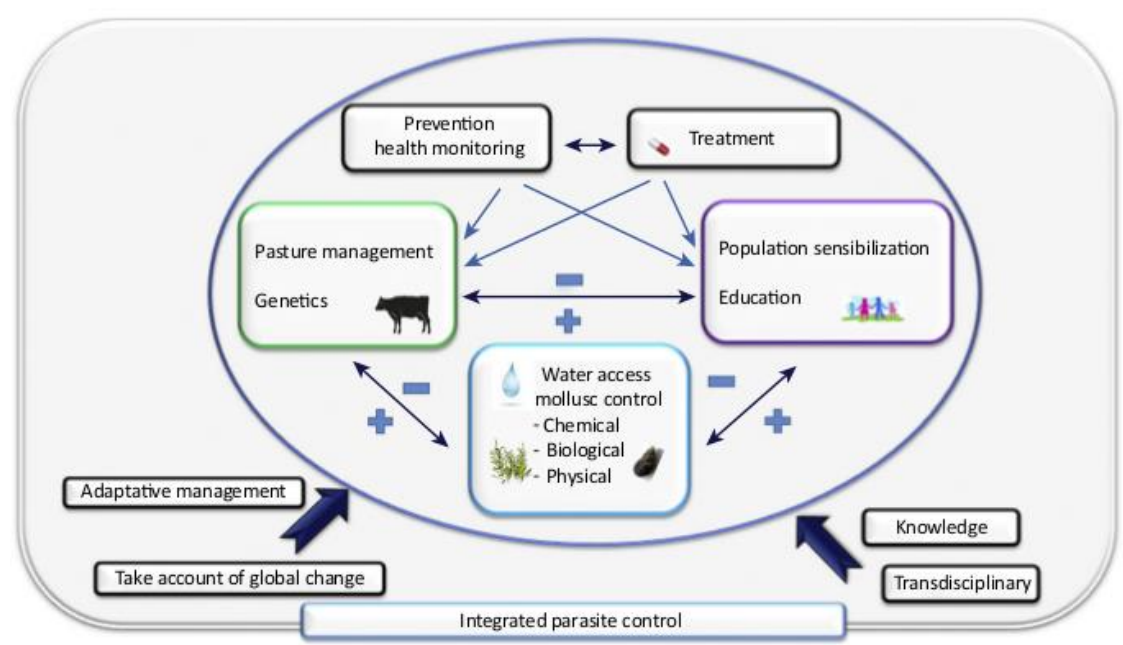

Figure 3 The three compartments of (i) water access (blue), (ii) livestock (green), and (iii) human habits (purple) can be linked to each other. It is important to have good management of all of these compartments to limit the emergence of fasciolosis. For that purpose, it is possible to monitor and prevent its circulation with several methods in the three parts. Treatments can be used for prevention in certain endemic areas in humans and animals. It is also important to promote transdisciplinary and integrated parasite control.

ultrasound, ELISA, and molecular approaches (Box 1). Such approaches detect infections rapidly and more accurately, but they are often more expensive and complicated [77,90,91].

If good preventative strategies have not been taken and humans are infected, they can be treated with TCBZ [90] or nitazoxanide. The latter is another drug used during the chronic stage of fasciolosis and for patients with low parasite burdens [29]. TCBZ resistance concerning humans has been reported in some endemic areas in The Netherlands, Chile, Turkey, and Peru [34].

Finally, in order to reduce the prevalence of the disease, it is important to control different factors and use several methods, such as vector control, health education, improvement of local health systems and chemotherapy [92] (Figure 3, Key Figure). In Central Vietnam, a study reported the effectiveness of an integrated control program on fasciolosis. This model could feasibly inform the initiatives in other countries where fasciolosis is prevalent (Tran Minh Quy, Doctor of Public Health thesis, University of Wollongong, 2016).

\section{Concluding Remarks}

Man-made constructions and livestock management can create good conditions for liver-fluke transmission. These new habitats can also favour the emergence of the disease in human populations due to human diets and unhygienic habits. The challenge of controlling fasciolosis can be met only if we deal with the complex interactions between the environment, hosts (snails, livestock, wildlife, humans), and human activities (see Outstanding Questions). It is essential to consider all of these factors, which are involved in a constantly changing world (climate, habitat fragmentation, pollution). The socioeconomic and ecological context of each country, region, city, and farm should be considered to prevent fasciolosis. Indeed, many studies focusing on schistosomiasis and other neglected tropical diseases have shown that applying an integrated control program is the most effective solution for preventing disease (re) emergence. The literature is still scarce regarding fasciolosis, and more systematic studies are needed. However, we believe that the key to successfully controlling this disease lies in applying good integrated control programs and local adaptive management practices.

\section{Acknowledgments}

We would like to express our gratitude to Jean-Pierre Pointier for valuable discussions on earlier drafts of the manuscript as well as to the reviewers for their constructive remarks. This study was financially supported by Labex CeMeb, the Tour du Valat, and the INEE CNRS through the Ecosan funding program.

\section{Resources}

http://who.int/neglected_diseases/preventive_chemotherapy/Newsletter10.pdf

"www.fao.org/fileadmin/user_upload/agns/news_events/Parasite\%20report\%20final\%20draft-25October2012.pdf

iiiwww.parc-camargue.fr/newsletter/guide_technique_2.pdf

\section{References}

1. Taylor, L.H. et al. (2001) Risk factors for human disease emergence. Philos. Trans. R. Soc. Lond. B Biol. Sci. 356, 983-989

2. Jones, K.E. et al. (2008) Global trends in emerging infectious diseases. Nature 451, 990-994

3. Cotruvo, J.A. et al., eds (2004) Waterborne Zoonoses: Identification, Causes, and Control, IWA Publishing

Rim, H.J. et al. (1994) Food-borne trematodes: Ignored or emerging? Parasitol. Today 10, 207-209

Keiser, J and Utzinger, J. (2009) Food-borne trematodiases. Clin. Microbiol. Rev. 22, 466-483

Fürst, T. et al. (2012) Global burden of human food-borne trematodiasis: A systematic review and meta-analysis. Lancet Infect. Dis. 12, 210-221

Hotez, P.J. et al. (2008) Helminth infections: the great neglected tropical diseases. J. Clin. Invest. 118, 1311-1321

8. Steinmann, P. et al. (2006) Schistosomiasis and water resources development: systematic review, meta-analysis, and estimates of people at risk. Lancet Infect. Dis. 6,411-425

Esteban, J.G. et al. (2002) High fascioliasis infection in children linked to a man-made irrigation zone in Peru. Trop. Med. Int. Health 7, 339-348

10. Morozova, E.V. et al. (2004) Polymorphism of the ND1 and CO1 mitochondrial genes in populations of liver fluke Fasciola hepatica. Russ. J. Genet. 40,817-820

11. Walker, S.M. et al. (2011) Population dynamics of the liver fluke, Fasciola hepatica: the effect of time and spatial separation on the genetic diversity of fluke populations in the Netherlands. Parasitology 138, 215-223

12. Mekky, M.A. et al. (2015) Human fascioliasis: A re-emerging disease in Upper Egypt. Am. J. Trop. Med. Hyg. 93, 76-79

13. Dreyfuss, G. et al. (2005) Fasciola hepatica: Epidemiological surveillance of natural watercress beds in central France. Parasitol. Res. 95, 278-282

14. Nzalawahe, J et al. (2015) Associations between trematode infections in cattle and freshwater snails in highland and lowland areas of Iringa Rural District Tanzania Parasitology 142, 1-10

15. Keyyu, J.D. et al. (2005) Epidemiology of Fasciola gigantica and amphistomes in cattle on traditional, small-scale dairy and largescale dairy farms in the southern highlands of Tanzania. Trop. Anim. Health Prod. 37, 303-314

16. Rojas, L. et al. (2010) Fascioliasis: can Cuba conquer this emerging parasitosis? Trends Parasitol. 26, 26-34

17. Chen, J.X. et al. (2013) An outbreak of human Fascioliasis gigantica in Southwest China. PLoS One 8, e71520

18. Bui, T.D. et al. (2015) Current status of fasciolosis in Vietnam: an update and perspectives. J. Helminthol. 1, 1-12 
19. Fentie, T. et al. (2013) Epidemiology of human fascioliasis and intestinal parasitosis among schoolchildren in lake Tana Basin, northwest Ethiopia. Trans. R. Soc. Trop. Med. Hyg. 107, $480-486$

20. Ashrafi, K. et al. (2015) The endemicity of human fascioliasis in Guilan province, northern Iran: The baseline for implementation of control strategies. Iran. J. Public Health 44, 501-511

21. Saijuntha, W. et al. (2018) Revealing genetic hybridization and DNA recombination of Fasciola hepatica and Fasciola gigantica in nuclear introns of the hybrid Fasciola flukes. Mol. Biochem. Parasitol. Published online July 3, 2018. http://dx.doi.org/ 10.1016/j.molbiopara.2018.06.004

22. Periago, M.V. et al. (2008) First phenotypic description of Fasciola hepatica/Fasciola gigantica intermediate forms from the human endemic area of the Nile Delta, Egypt. Infect. Genet. Evol. 8, 51-58

23. Hurtrez-boussès, S. et al. (2001) Dynamics of host-parasite interactions: the example of population biology of the liver fluke (Fasciola hepatica). Microbes Infect. 3, 841-849

24. Andrew, S. (1999) The life cycle of Fasciola hepatica. In Fasciolosis (Dalton, J., ed.), pp. 1-29, CABI

25. Valero, M.A. et al (2009) Fluke ego characteristics for the diagnosis of human and animal fascioliasis by Fasciola hepatica and F. gigantica. Acta Trop. 111, 150-159

26. Mas-Coma, S. (2005) Epidemiology of fascioliasis in human endemic areas. J. Helminthol. 79, 207-216

27. Nyindo, M. and Lukambagire, A.H. (2015) Fascioliasis: an ongoing zoonotic trematode infection. BioMed Res. Int. 2015,

28. Mera y Sierra, R.L. et al. (2011) Human fascioliasis in Argentina: retrospective overview, critical analysis and baseline for future research. Parasit. Vectors 4, 104

29. Zumaquero-Ríos, J.L. et al. (2013) Fascioliasis and intestinal parasitoses affecting schoolchildren in Atlixco, Puebla State, Mexico: epidemiology and treatment with Nitazoxanide. PLoS Negl. Trop. Dis. $7, \mathrm{e} 2553$

30. Fürst, T. et al. (2012) Trematode Infections. Infect. Dis. Clin. North Am. 26, 399-419

31. Torgerson, P. and Claxton, C. (1999) Epidemiology and control. In Fasciolosis (Dalton, J., ed.), pp. 113-151, CABI

32. Mulcahy, G. and Dalton, J.P. (2001) Cathepsin L proteinases as vaccines against infection with Fasciola hepatica (liver fluke) in ruminants. Res. Vet. Sci. 70, 83-86

33. FAO/WHO (2014) Multicriteria-based ranking for risk management of food-borne parasites. Microbiol. Risk Assess. Ser. 23, 302

34. Kelley, J.M. et al. (2016) Current threat of triclabendazole resistance in Fasciola hepatica. Trends Parasitol. 32, 458-469

35. Prepelitchi, L. et al. (2011) (Gastropoda: Lymnaeidae) in Wetlands of Northeastern Argentina. Zool. Stud 50, 164-176

36. Pointier, J.P. et al. (2009) Distribution of Lymnaeidae (Mollusca: Pulmonata), intermediate snail hosts of Fasciola hepatica in Venezuela. Mem. Inst. Oswaldo Cruz 104, 790-796

37. Vásquez, A. et al. (2009) Distribución y preferencia de hábitats de moluscos hospederos intermediarios de Fasciola hepatica en Cuba. Rev. Cubana Med. Trop. 61, 248-253

38. Correa, A.C. et al. (2010) Bridging gaps in the molecular phylogeny of the Lymnaeidae (Gastropoda: Pulmonata), vectors of Fascioliasis. BMC Evol. Biol. 10, 381

39. Hamed, N. et al. (2009) Natural infection of Fasciola hepatica (Trematoda: Fasciolidae) in Bulinus truncatus (Gastropoda: Planorbidae) in northern Tunisia. J. Helminthol. 83, 271-273

40. Relf, V. et al. (2009) Evidence of Fasciola hepatica infection in Radix peregra and a mollusc of the family Succineidae in Ireland. Vet. Parasitol. 163, 152-155

41. Trouve, S. et al. (2005) Ecological components and evolution of selfing in the freshwater snail Galba truncatula. J. Evol. Biol. 18, 358-370

42. Lounnas, M. et al. (2017) Self-fertilization, long-distance flash invasion and biogeography shape the population structure of Pseudosuccinea columella at the worldwide scale. Mol. Ecol. 12, 3218-3221

43. Meunier, $\mathrm{C}$. et al (2004) Field and experimental evidence of preferential selfing in the freshwater mollusc Lymnaea truncatula (Gastropoda, Pulmonata). Heredity (Edinb) $92,316-322$

44. Meunier, C. et al. (2001) Lack of molluscan host diversity and the transmission of an emerging parasitic disease in Bolivia. Mol. Ecol. 10, 1333-1340

45. Lodge, D.M. et al. (1998) Predicting impact of freshwater exotic species on native biodiversity: challenges in spatial scaling. Aust. J. Ecol. 23, 53-67

46. Loo, S.E. et al. (2007) Freshwater invasions: Using historical data to analyse spread. Divers. Distrib. 13, 23-32

47. Diaw, O.T. et al. (1990) Prolifération de mollusques et incidence sur les trématodoses dans la région du delta et du lac de Guiers après la construction du barrage de Diama sur le fleuve Sénégal. Helminthologie 43, 499-502

48. Esteban, J.G. et al. (2003) Hyperendemic fascioliasis associated with schistosomiasis in villages in the Nile Delta of Egypt. Am. J. Trop. Med. Hyg. 69, 429-437

49. Moukrim, A. and Rondelaud, D. (1992) Vertical spatial behabiour patterns of lymnea truncatula in relation with origin of snails, infection with Fasciola hepatica, and experimental environment. Ann. Parasitol. Hum. Comp. 6, 174-179

50. Alba, A. et al. (2016) Assessment of the FasciMol-ELISA in the detection of the trematode Fasciola hepatica in field-collected Galba cubensis: a novel tool for the malacological survey of fasciolosis transmission. Parasit. Vectors 9,22

51. Martínez-Valladares, M. et al. (2013) Prevalence of gastrointestinal nematodes and Fasciola hepatica in sheep in the northwest of Spain: relation to climatic conditions and/or man-made environ-mental modifications. Parasit. Vectors 6, 282

52. Afshan, K. et al. (2014) Impact of climate change and man-made irrigation systems on the transmission risk, long-term trend and seasonality of human and animal fascioliasis in Pakistan. Geospat. Health 8, 317-334

53. Rondelaud, D. et al. (2009) La limnée tronquée: - Un mollusque d’intérêt médical et vétérinaire. (1st edn). Presses universitaires de Limoges

54. Singh, A. and Agarwal, R.A. (1988) Possibility of using latex of euphorbiales for snail control. Sci. Total Environ. 77, 231-236

55. Hammond, J.A. et al. (1994) Eucalyptus: A sustainable self delivery molluscicide? Vet. Res. Commun. 18, 359-365

56. Chawech, R. et al. (2016) A study of the molluscicidal and larvicidal activities of Citrullus colocynthis L. leaf extract and its main cucurbitacins against the mollusc Galba truncatula, intermediate host of Fasciola hepatica. Pest Manag. Sci. 73, 1473-1477

57. Perera G et al (1990) Effectiveness of three biological control agents against intermediate hosts of snail-mediated parasites in Cuba Malacol Rev 23, 47-52

58. Perera, G. et al. (1993) Biological control of snail intermediate hosts by competitor thiarid snails in Cuba. J. Med. Appl. Matacol. 97, 97-101

59. Rondelaud, D. et al. (2006) The control of Galba truncatula (Gastropoda: Lymnaeidae) by the terrestrial snail Zonitoides nitidus on acid soils. Biol. Control 39, 290-299

60. Chlyeh, G. et al. (2006) Spatio-temporal distribution of freshwater snail species in relation to migration and environmental factors in an irrigated area from Morocco. Hydrobiologia 553, 129-142

61. Waterkeyn, A. et al. (2010) Invertebrate dispersal by aquatic mammals: A case study with nutria Myocastor coypus (Rodentia, Mammalia) in Southern France. Hydrobiologia 654, 267-271

62. Viana, D.S. et al. (2013) Migratory strategies of waterbirds shape the continental-scale dispersal of aquatic organisms. Ecography 36, 430-438

63. Raunelli, F. and Gonzalez, S. (2009) Strategic control and prevalence of Fasciola Hepatica in Cajamarca, Peru. A Pilot Study. J. Appl. Res. Vet. 7, 145-152

64. Schweizer, G. et al. (2007) Prevalence of Fasciola hepatica in the intermediate host Lymnaea truncatula detected by real time TaqMan PCR in populations from 70 Swiss farms with cattle husbandry. Vet. Parasitol. $150,164-169$

65. Novobilskÿ, A et al. (2015) Impact of meteorological and environmental factors on the spatial distribution of Fasciola hepatica in beef cattle herds in Sweden. BMC Vet. Res. 11, 128

66. Martins, I.V.F. et al. (2014) of bovine fasciolosis and associated factors in south Espírito Santo, Brazil: an update. Braz. J. Vet. Parasitol. 23, 23-29

67. Olsen, A. et al. (2015) Prevalence, risk factors and spatial analysis of liver fluke infections in Danish cattle herds. Parasit. Vectors 8, 160

68. Mas-Coma, S. et al. (2001) Fasciola hepatica and lymnaeid snails occurring at very high altitude in South America. Parasitology 123, S115-S127

69. Semyenova, S.K. et al. (2006) Genetic differentiation in Eastern European and Western Asian population of the liver fluke, Fasciola hepatica, as revealed by mitochondrial NAD1 andd COX1 genes. J. Parasitol. 92 , 525530

70. Walker, S.M. et al. (2007) Evidence for multiple mitochondrial lineages of Fasciola hepatica (liver fluke) within infrapopulations from cattle and sheep. Parasitol. Res. 101, 117-125

71. Ashrafi, K. et al. (2015) Distribution of Fasciola hepatica and F. gigantica in the endemic area of Guilan, Iran: Relationships between zonal overlap and phenotypic traits. Infect. Genet. Evol. 31, 95-109

72. Knubben-Schweizer, G. and Torgerson, P.R. (2015) Veterinary parasitology bovine fasciolosis: control strategies based on the location of Galba truncatula habitats on farms. Vet. Parasitol. 208, 77-83

73. De Roeck, E. et al. (2014) Fine-scale mapping of vector habitats using very high resolution satellite imagery: A liver fluke casestudy. Geospat. Health 8, S671-S683

74. Charlier, J. et al. (2014) Longitudinal study on the temporal and micro-spatial distribution of Galba truncatula in four farms in Belgium as a base for small-scale risk mapping of Fasciola hepatica. Parasit. Vectors 7, 528

75. Suon, S. et al. (2006) Seasonal differences in the incidence of infection with Fasciola gigantica in Cambodian cattle. Trop. Anim. Health Prod. 38, 23-28

76. Vreni, J. et al. (2014) Prevalence of Fasciola gigantica infection in slaughtered animals in south-eastem Lake Chad area in relation to husbandry practices and seasonal water levels. BMC Vet. Res. 10, 81

77. Beesley, N.J. et al. (2017) Fasciola and fasciolosis in ruminants in Europe: Identifying research needs. Transbound. Emerg. Dis. Published online October 6, 2017. http://dx.doi.org/10.1111/ thed.12682

78. Fairweather, I. (2011) Reducing the future threat from (liver) fluke: Realistic prospect or quixotic fantasy? Vet Parasitol. 180, 133-143

79. Munita, M.P. et al. (2016) Six-year longitudinal study of Fasciola hepatica bulk milk antibody ELISA in the dairy dense region of the Republic Ireland. Prev. Vet. Med. 134, 16-25

80. Molina-Hernández, V. et al. (2015) Fasciola hepatica vaccine: We may not be there yet but we're on the right road. Vet. Parasitol. 208, 101-111

81. Toet, H. et al. (2014) Liver fluke vaccines in ruminants: Strategies, progress and future opportunities. Int. J. Parasitol. 44, 915-927

82. Knubben-Schweizer, G. et al. (2010) Control of bovine fasciolosis in dairy cattle in Switzerland with emphasis on pasture management. Vet. J. 186, 188-191

83. Baker, R.L. and Gray, G.D. et al. (2004) Appropriate breeds and breeding schemes for sheep and goats in the tropics. In Worm Control for Small Ruminants in Tropical Asia (Sani, R., ed.), pp. 63-95, ACIAR Monograph $\mathrm{N}^{\circ} 113$

84. Roberts, J.A. et al. (1997) Acquisition of resistance against Fasciola gigantica by Indonesian thin tail sheep. Vet. Parasitol. 73, 215-224

85. Pleasance, J. et al. (2011) Resistance to liver fluke infection in the natural sheep host is correlated with a type-1 cytokine response. Parasite Immunol. 33, 495-505

86. Raissy, M. and Ansari, M. (2012) Seroprevalence of human fasciolosis in a new-emerging focus of fasciolosis in Yasuj District, Southwest of Iran. Iran. J. Parasitol. 7, 73-79

87. Amoah, P. et al. (2005) Irrigated urban vegetable production in Ghana: Sources of pathogen contamination and health risk elimination. Irrig. Drain. 54, S49-S6

88. Parkinson, M. et al. (2007) Endemic human fasciolosis in the Bolivian Altiplano. Epidemiol. Infect. 135, 669

89. Esteban, J.G. et al. (1997) Presence of very high prevalence and intensity of infection with Fasciola hepatica among Aymara children from the Northern Bolivian Altiplano. Acta Trop. 66, 1-14

90. WHO (2007) Report of the WHO Informal Meeting on Use of Triclabendazole in Fascioliasis Control, pp. 1-31, WHO

91. Cwiklinski, K. et al. (2016) A prospective view of animal and human fasciolosis. Parasite Immunol, 38, 558-568

92. Molyneux, D.H. (2006) Control of human parasitic diseases: context and overview. Adv. Parasitol. 61, 1-45

93. Cringoli, G. et al. (2010) FLOTAC: New multivalent techniques for qualitative and quantitative copromicroscopic diagnosis of parasites in animals and humans. Nat. Protoc. 5, 503-515

94. Charlier, J. et al. (2007) Associations between anti-Fasciola hepatica antibody levels in bulk-tank milk samples and production parameters in dairy herds. Prev. Vet. Med. 78, 57-66

95. Mezo, M. et al. (2010) Field evaluation of the MM3-SERO ELISA for detection of anti-Fasciola IgG antibodies in milk samples from individual cows and bulk milk tanks. Parasitol. Int. $59,610-615$

96. Mezo, M. et al. (2004) An ultrasensitive capture ELISA for detection of Fasciola hepatica coproantigens in sheep and cattle using a new monoclonal antibody (Mm3). J. Parasitol. 90, 845852

97. Martínez-Sernández, V. et al. (2016) Rapid enhanced MM3 COPRO ELISA for detection of Fasciola coproantigens. PLoS Negl. Trop. Dis. 10, 1-20

98. Martínez-Valladares, M. and Rojo-Vázquez, F.A. (2016) Loopmediated isothermal amplification (LAMP) assay for the diagnosis of fasciolosis in sheep and its application under field conditions. Parasit. Vectors 9, 73 